and produced without difficulty from a constituent of the nitrogenous cell structures, which is able to produce a state of the circulation like that present in wound-shock. It was found that the effect was not due to a dilatation of the arterial part of the system, as was known to be the case in the fall of blood-pressure brought about by vaso-motor reflexes. Here the similarity to traumatic toxæmia showed itself again, because it was known that arterial dilatation was not present in this state. Next, Dale and Richards, by a number of ingenious experiments, were able to localise the effect in the capillaries, which became widely dilated and thus capable of taking up the greater part of the blood in the body, leaving the heart nearly empty, with too meagre a supply to carry on the circulation with any degree of efficacy. It is to be admitted that we have not yet definite proof that it is histamine itself which is responsible for the toxæmia of injury. But that the agent is something which acts in the same way is made clear by the observations that have been made on wounded men. The determinations of the volume of the blood in circulation, made by N. M. Keith, may be especially mentioned. Keith showed that, in severe cases, it may be reduced to little more than half the normal amount, although scarcely any has actually been lost by hæmorrhage. The method used was that of introducing into a vein a known quantity of an innocuous dye which does not pass through the walls of the blood-vessels, and, after a short interval, taking a sample of the blood and finding how much the dye has been diluted.

If the toxæmia is severe, a second property of the poison shows itself. This is an effect on the walls of the capillaries such that they allow the liquid part of the blood to escape by filtration. In this way the volume of the blood is still further reduced.

The treatment, in principle, is obvious. Restore the blood-volume. It would appear that when blood has been lost it ought to be replaced by blood. The case of traumatic toxæmia is not so clear at once, because blood has not been actually lost, and it should be possible to keep un an effective circulation by some other liquid until the poison is got rid of and the pooled blood returned to circulation. In fact, as experience increased, it was realised that the important matter is to maintain the volume in circulation, whether by blood or other solution. An innocuous fluid seemed to serve practically as well as blood, and had the advantage of being always at hand and in as large a quantity as required.

As to the properties of such a solution, it was soon found that a simple saline solution is very rapidly lost from the circulation and is useless. It is necessary to add to it some colloid with an osmotic pressure, such as gelatin or gum acacia. The colloid does not pass through the walls of the blood-vessels, and its osmotic pressure causes an attraction of water to balance that lost by filtration. Thus, although the slow circulation incidental to a small volume of blood is inadequate, this very quantity, if diluted to normal volume, is able to serve effectively. Comparing the oxygen carried by the red corpuscles to railway passengers, it will be realised that if we have a limited number of trains, we can carry more passengers in a given time if the velocity of the trains is increased. Animal experiments made by Gasser showed that this is actually the case with the blood. After a loss of blood the injection of gum-saline might even raise the supply of bloodcorpuscles to a level beyond what it was before the hæmorrhage.

The general conclusion is that the volume of the liquid in circulation must be kept up to its normal value, whatever this liquid may be. Of course, the number of red corpuscles cannot be allowed to fall below some particular value, and it has been found that about one-quarter of the normal quantity is the lowest compatible with life. If they fall below this, moreover, there is no production of new corpuscles.

In the later stages of the war gum-saline was largely used in the British, American, and French Armies, and is reported to have saved many lives. Unfortunately, if too long a time is allowed to elapse before treatment, nothing avails, not even transfusion of blood. Hence the importance of the early use of intravenous injection, and also of removal of the injured tissue by operation. As the war progressed, these procedures were, therefore, pushed more and more forward to the battle area, and with more and more favourable results.

\title{
Characteristics of Pigments in Early Pencil Writing.
}

By C. Ainsworth Mitchell.

$\mathrm{P}$ ENCIL pigments may be classified in the following groups: (I) Metallic lead or alloys of lead; (2) graphite cut from the block; (3) early composite pigments containing graphite, sulphur, resins, etc., but no clay; (4) graphite powder compressed into blocks; and (5) composite pigments containing graphite with clay and other ingredients. These pigments usually show distinctive microscopic characteristics in the marks which they produce.

$$
\text { NO. } 2627 \text {, VOL. IO5] }
$$

When examined under the microscope with a magnification of about twenty diameters and the light at right angles, ordinary lead shows, in its vertical markings on paper, a series of irregularly distributed patches, uniformly and brilliantly lit up, and marked with regular vertical striations which have the appearance of ridges. In the case of Borrowdale graphite (Fig. r) the vertical lines show relatively few brilliant straight striations (due to siliceous impurities), and when these occur in the 
heavier strokes they are disjointed and irregular. The fibres of the paper may be brilliantly lit up by particles of adhering graphite which reflect the light, especially in those places showing a metallic lustre to the naked eye. Less pure forms of graphite show more numerous striations, but these are always more or less disjointed and irregular, and quite distinct from the fine striations in modern pencil markings.

The composite pigments (containing sulphur) in early specimens of pencils in South Kensington Museum, which Mr. T. H. Court kindly placed at my disposal, show a faint greyish pigment, with occasional striations, whilst Brockedon's graphite (1843) (Fig. 2) and other kinds of compressed graphite produce lines which show a rich black pigment with silvery dashes and lines distributed fairly uniformly all over the field.

Modern pencil compositions, mainly of graphite, clay, and wax, all have a similar microscopic appearance in the vertical lines made by them on paper, which is quite different from the markings of the old pencils of $\mathrm{naturat}$ graphite, and in most cases from those made from the old com pressed graphite pow der. In the modern pigments the fine siliceous particles, derived from the clay and impurities in the graphite, are evenly distributed, and appear in the pigment on paper as fine beaded striations, which are uniform and parallel throughout the $1 \mathrm{in}$ e (Fig. 3). C h e m i c a 1 methods of distin guishing betwee $n$ these pigments have been described by the present writer (J. Soc. Chem. Ind., I9I9, xxxviii., 383T).

Some particulars of early pencil markings are given in a curious book by $\mathrm{C}$. T. Schönemann (Versuch eines Systems der Diplomatik, Leipzig, 1818,2 vols.) upon the codices preserved in the libraries in Germany. In vol. ii. (p. 108) it is asserted that lines in blacklead (Reisblei) had been drawn on the "Codex Berengarii Turonensis" of the eleventh or twelfth century, which was in the Wolfenbüttel library. The "Codex Guidonis Aretini de Musica" (eleventh or twelfth century) in the Göttingen library contained vertical and horizontal lines showing traces of blacklead (p. I I2), whilst the "Codex Theophili" (twelfth century) in the Wolfenbüttel library showed very fine vertical lines in blacklead.

Now, as graphite was not known until about I56o, it is obvious that Schönemann mistook the NO. $2 \overline{0} 2$ VOL. IO5] markings in ordinary metallic lead for graphite. Through the kindness of Mr. J. P. Gilson, of the MSS. department, I have been able to examine specimens of early pencil marks in the writing and drawings in manuscripts in the British Museum. The earliest example was a drawing in the Stowe MSS., "Arms of Ancient Nobilitie" (705), of the early seventeenth century. The particles composing the lines of this drawing all reflected the light brilliantly, but were much smaller, and lacked the striations which are characteristic of metallic lead. On the other hand, the lines had not the appearance of any form of graphite, the particles being disjointed and not showing any connecting interrupted striations, as are often to be seen in lines of graphite having a metallic lustre. It is therefore probable that this

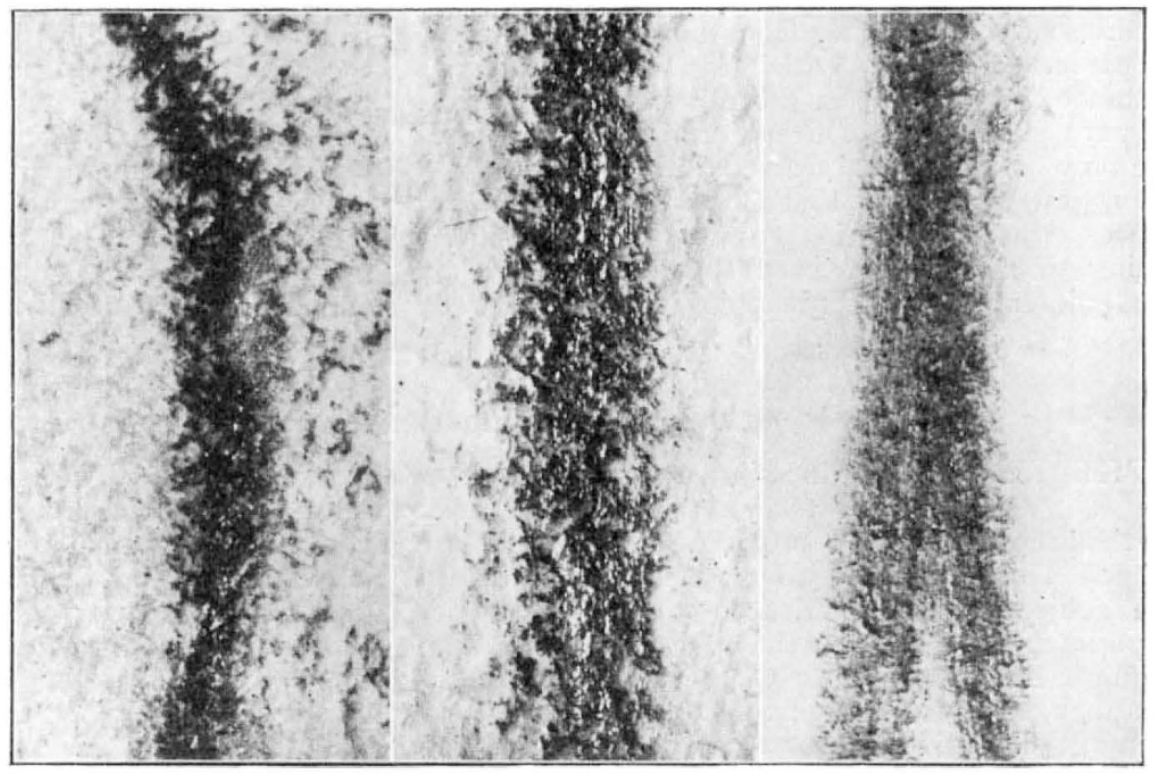

Fig. 2.-Brockedon's compressed FiG. 3.-Typical modern composite graphite, r843. (Mark made by specimen in Geologiral

drawing was done with a metallic pencil in which lead did not predominate.

A later MS. (169I) (Add. 22,550) includes drawings in which the lines show the large isolated particles with the vertical striations characteristic of metallic lead. In another Stowe MS., 686 (circ. 1630 ), the lines in the drawings have the appearance of ordinary graphite. The pencil markings in two note-books of Sir Thomas Cotton (Harley, 6or8, about $\times 630-40$ ) and Cotton Appendix, xlv. (I640-44), have all the characteristics of graphite.

The writing in Lord Hardwicke's "Notes on Briefs" (I I I 8 ) is undoubtedly in graphite, but a drawing by Vertue (Add. MS. 2III) (I74I) has the appearance of metallic pigment. A note-book of Hogarth (Egerton MS. 30II) (prior to I753) contains heavy pencil writing, the pigment of which is a particularly rich graphite. 
The pencil outline of a drawing on the top of ink in another of Hogarth's note-books is also in typical graphite. The lines in the drawings of a later volume of Stowe MSS. (993), about 1747, show fine interrupted striæ, such as are frequently noticeable in the marks made by pure graphite. In "Heraldic Collections" (Stowe MS. 66I) of $\mathrm{r}_{763}-64$ the pigment in the drawings of the coatsof-arms is also in graphite, and shows the fibres of the paper lit up by adherent particles. An interesting example of graphite markings is to be seen in a letter from Prof. Herrmann ( 1780 ) from Strasbourg (Add. MS. 22,935, fol. 140b). This contains a pencil drawing of a fish, in which the pigment has formed branching striations along the lines of the paper fibres.

Flaxman was in the habit of making drawings on the backs of the envelopes of letters received by him at Buckingham Street, Fitzroy Square, and a series of these, dating from about 1800 to 1814 , is preserved in the British Museum. In every instance the pigment in these drawings is typical of pure graphite, and even interrupted striations are only of exceptional occurrence.

In. view of the fact that Conté's composite clay process was invented in 1795 in Paris, it is interesting to note that a card sent to Flaxman by the painter Fleury Epinat, of Lyons, between
I 805 and I8I 4 was written with a pencil producing the characteristic fine regular beaded striations of the modern type of pencil. This is the first instance noted of the occurrence of writing in a composition pigment in the MSS. in the Museum.

Of the other manuscripts and drawings of the early nineteenth century, mention may be made of a letter of Byron (about I809) which is written in a particularly brilliant graphite, and of the pencil corrections made by Keats (about 1820) in his manuscript of "Hyperion," which are also in pure graphite. The same characteristics of rich pigment deposit, showing only scanty, irregular, broken striations, may also be seen in a letter of Lord Wellesley written about r828.

The manufacture of graphite pencils by the original method of cutting from the block was continued until about r869, overlapping the modern process; but, as the old pencils must have been widely distributed, it is not surprising that the characteristics of pure graphite are frequently to be found in writing, and especially in drawings, for several years after that date. Hence it is quite in accordance with the development of the industry that the note-book of James Thomson, the author of "The City of Dreadful Night," for the year 1869 should be written with a pencil which produced no silvery striations.

\section{The Relationship of Education to Research in Aeronautics.}

$\mathrm{HE}$ relation of education to research is a
simple one in most fields of scientific work, in that the universities provide both one and the other. This simplicity cannot, however, extend to the subject of aeronautics, because the cost of experimentation is so great and the organisation required so complex. In the future the universities may perhaps be equipped even for this extension of their activities, but at the present time, and for many years to come, the experimental work will in general be beyond their means. The Government, however, for its own sake, needs to continue to carry on aeronautical research, and the question naturally arises: What are to be the relations between the Government research establishments and the university teaching establishments? The Committee appointed in October, I918, by Lord Weir to advise on this matter has now reported, and its recommendation is to merge the staffs undertaking these two classes of work. At the present time it is scarcely practicable or wise to found more than one school of aeronautics, and the Committee selects the Imperial College of Science as its home, suggesting that the staff of the school should for the most part be composed of those members of the Government research establishments who are best qualified for the work, and can be permitted to spend part of their time at the Imperial College.

The Committee also provides that the Advisory Committee for Aeronautics should come to an end, and that its former powers should-with certain additions-be made over to a new body, the Aero- nautical Research Committee. The Advisory Committee has had a very distinguished history. Its composition was mainly non-official, and it became a watchful and highly independent body able and ready to intervene in any matter where it thought such intervention was required. With the many reorganisations of Air Service matters during the war, whether relating to the R.N.A.S., the R.F.C., the Air Board, the Air Ministry, or the R.A.F., it became the one continuously operating body, and rendered services to the State of a value which can be realised only by those who kept in touch with its wide activities. The Education and Research Committee endeavours to pay tribute to the Advisory Committee, and it must have had some difficulty in finding words appropriate to the occasion.

It seems that the Government took definite decisions some six months ago that an Aeronautical Research Committee should be created to replace the existing Advisory Committee; that, in addition, research work should be undertaken by a Research Association to be formed by the Department of Scientific and Industrial Research, on the usual terms, if the industry should so desire; and that the Imperial College should be the educational centre (although applications from provincial universities for grants would be considered). The Committee, taking note of these decisions, suggests that the new Aeronautical Research Committee (A.R.C.) should supervise both research and education. Any plan for the supervision of research needs to take into account NO. 2627 , VOL. IO5] 